\title{
MYB3 Plays an Important Role in Lignin and Anthocyanin Biosynthesis Under Salt Stress Condition in Arabidopsis
}

\section{Daewon Kim}

University of Missouri

\section{Su Jeong Jeon}

Gyeongsang National University

\section{Samantha Yanders}

University of Missouri

\section{Sung-Chul Park}

Korea Research Institute of Bioscience and Biotechnology

Ho Soo Kim ( $\nabla$ hskim@kribb.re.kr)

Korea Research Institute of Bioscience and Biotechnology https://orcid.org/0000-0002-3115-6783

\section{Sewon Kim}

Rural Development Administration

\section{Research Article}

Keywords: MYB3, Lignin, Anthocyanin, transcriptional repressor, phenylpropanoid biosynthesis

Posted Date: March 3rd, 2022

DOI: https://doi.org/10.21203/rs.3.rs-1386841/v1

License: (9) (i) This work is licensed under a Creative Commons Attribution 4.0 International License. Read Full License 


\section{Abstract}

Salinity stress is one of the major factors in the reduction of plant growth and crop yield worldwide. To improve our ability to grow crops in high-salinity environments, plant responses to salinity stress must be tightly controlled. Here, in order to further understand the precise regulation of plant responses under high salinity conditions, the function of the MYB3 transcription factor was studied as a repressor to control excessive accumulation of lignin and anthocyanin under salt stress conditions. Nuclear-localized MYB3 forms a homodimer. It is ubiquitously expressed, especially in vascular tissues, and its expression is highly induced by $\mathrm{NaCl}$ in various tissues such as roots, leaves, stems, and flowers. myb3 mutant plants exhibited longer root growth in high $\mathrm{NaCl}$ conditions than wild-type plants. However, several $\mathrm{NaCl}$ responsive or signaling genes were not significantly altered in myb3 compared to wild-type. Interestingly, high accumulation of lignin and anthocyanin was displayed in $m y b 3$, and the expression of genes involved in lignin and anthocyanin biosynthesis, such as PAL 1, C4H, COMT, 4CL3, DFR and LDOX, sharply increased in myb3 compared to those of wild-type plants under $\mathrm{NaCl}$ treatment. According to yeast-two hybrid screenings, various transcription factors, including anthocyanin regulators TT8 and EGL3, were isolated as MYB3 interacting proteins. MYB3 was characterized as a transcriptional repressor and its repressor domain is located in the C-terminus of MYB3. Overall, these results suggest that nuclearlocalized MYB3 functions as a transcriptional repressor for the control of lignin and anthocyanin accumulation under salinity stress conditions.

\section{Key Message}

MYB3 functions to inhibit excessive biosynthesis of lignin and anthocyanin due to high salinity conditions.

\section{Introduction}

Regulation of gene expression at the transcription level controls many crucial biological processes in eukaryotes (Spitz and Furlong, 2012). An estimated 7\% of the plant genome encodes for transcription factors (TFs); these can be divided to six groups according to typical DNA-binding motifs (AP2/ERF, MYB, BZIP, WRKY, MYC and NAC) (Century et al., 2008; Hwang et al., 2014). The MYB proteins belong to a large family of transcription factors in eukaryotic organisms (Katiyar et al., 2012). Depending on the numbers of adjacent imperfect repeats, MYB proteins in plants are classified into five subfamilies: R1-, R2-, R2R3-, R1R2R3-MYB (3R-MYB), and 4R-MYB, with the last group containing four R1/R2-like repeat motifs structures with a length of approximately 50-55 amino acids (Ambawat et al., 2013). Each MYB domain forms three a-helices, with the second and third helices building a helix-turn-helix structure that intercalates in the major DNA groove when the MYB protein binds to DNA (Dubos et al., 2010). The R2R3MYB proteins, which have two adjacently located repeats in the N-terminal (R2 and R3) and a highly variable $\mathrm{C}$-terminal domain, are unique to higher plants and are the predominant family of MYB proteins in plants (Ambawat et al., 2013; Dubos et al., 2010). R2R3-MYB transcription factors play important roles in regulating plant development and growth, physiological mechanisms, biotic and abiotic stress 
responses in plants. Arabidopsis MYB72 plays an important role in roots during the early signaling steps of induced systemic resistance mediated by beneficial fungi and bacteria (Segarra et al., 2009; Van der Ent et al., 2008). R2R3-type MYB60 and MYB96 proteins works through the ABA signaling cascade to regulate stomatal movement (Cominelli et al., 2005). MYB96-mediated ABA signals enhance plant pathogen resistance by elevating salicylic acid biosynthesis (Seo and Park, 2010).

Phenylpropanoid is a natural product derived from the amino acid I-phenylalanine through deamidation by a I-phenylalanine ammonia degrading enzyme (PAL) (Biała and Jasiński, 2018). The phenylpropanoid pathway serves as a source of abundant metabolites required for the biosynthesis of lignin in plants and serves as a starting point for the production of many other important compounds such as flavonoids, coumarins and anthocyanins (Fraser and Chapple, 2011). Phenylpropanoids, especially lignin and anthocyanin, contribute to all aspects of plant responses towards biotic and abiotic stimuli (Vogt, 2010). In previous studies, several R2R3-type MYB TFs have been shown to be involved in the regulation of phenylpropanoid and flavonoid biosynthesis. MYB11/PFG1, MYB12/PFG1 and MYB111/PFG3 share significant structural similarity to one another and display very similar target gene specificity for several genes which control of flavonoid biosynthesis in plant tissue, including CHALCONE SYNTHASE, CHALCONE ISOMERASE, FLAVANONE 3-HYDROXYLASE and FLAVONOL SYNTHASE1 (Stracke et al., 2007). In Arabidopsis, MYB75 (PAP1), MYB90 (PAP2), MYB113 (PAP3), and MYB114 (PAP4) paralogs display highly conserved protein sequences with TTG1- and bHLH-dependent late anthocyanin pathway genes in vegetative tissues, and anthocyanin contents is strongly accumulated in the plants through this pathway (Gonzalez et al., 2008). Furthermore, proanthocyanidins (PAs) biosynthesis is dependent on the transcriptional activity of R2R3-type MYB123/TT2 and MYB5 and R/B-like bHLH (GL3/bHLH001, EGL3/bHLH002, and TT8/bHLH042) transcription factors, which form ternary complexes (MBW) with TRANSPARENT TESTA GLABRA1 (TTG1), a WD repeat-containing protein in the seed coat of Arabidopsis (Xu et al., 2014). Recently, MYB5 was proposed to be partially redundant with MYB123/TT2 in regulating the heat stress response in Arabidopsis (Jacob et al., 2021).

We previously reported that the MYB3 transcription factor interacts with the C-terminal of Arabidopsis CPL1 phosphatase under $\mathrm{NaCl}$-and ABA-treated conditions (Bang et al., 2008). Here, MYB3 is further characterized as an important growth regulator under high salinity conditions. MYB3 is highly expressed by $\mathrm{NaCl}$ and forms homodimer in the nucleus. NLS is located in the N-terminal of MYB3. According to yeast two-hybrid screening, several transcription factors involved in phenylpropanoid and flavonoid biosynthesis strongly interact with MYB3. Lignin and anthocyanin are significantly reduced in myb3. All together, these results suggest that nuclear-localized MYB3 interacts with other transcription factors to function as a transcriptional repressor for the regulation of excessive lignin and anthocyanin accumulation under salinity stress conditions.

\section{Materials And Methods}

\section{Plant materials and growth conditions}




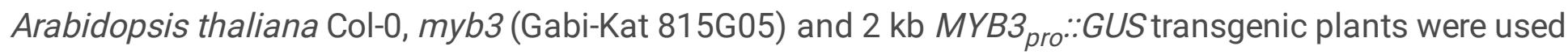
in this study. Seeds were sterilized by soaking in $1 \%$ bleach solution for $10 \mathrm{~min}$ followed by washing five times with sterilized water. Surface-sterilized seeds were sown on 1/2 Murashige and Skoog (MS) agar medium including $1 \%(\mathrm{w} / \mathrm{v})$ sucrose and $0.5 \%(\mathrm{w} / \mathrm{v})$ phytagel as well as $0.05 \%(\mathrm{w} / \mathrm{v}) \mathrm{MES}$. pH was adjusted to approximately 5.7 using $\mathrm{KOH}$. Seeds and plates were kept for 3 days at $4^{\circ} \mathrm{C}$ in the dark, and then subsequently transferred to a growth chamber with $16 \mathrm{~h}$ of light illumination per day and $70 \%$ humidity at $22^{\circ} \mathrm{C}$.

\section{Isolation of protoplasts and analysis of subcellular localization}

Full-length, $\mathrm{N}$ - or C-terminal MYB3 CDS for the GFP-fused constructs was prepared with a PCR reaction and fused to the 5 ' end of GFP in the pENSOTG GFP vector for transient expression. In order to isolate Arabidopsis protoplasts, the four-week-old plants were incubated with $1 \mathrm{M}$ mannitol for $30 \mathrm{~min}$. $30 \mathrm{~mL}$ of $0.22 \mu \mathrm{m}$ filter-sterilized enzyme solution was added, which contained $10 \mathrm{mM}$ MES-KOH (pH 5.7), $0.4 \mathrm{M}$ mannitol, $1 \mathrm{mM} \mathrm{CaCl}_{2}, 1 \%$ cellulase (Onozuka R-10), 0.25\% macerozyme (R-10) and 1\% BSA (Goldbio) and $0.035 \% \beta$-mercaptoethanol (Kim et al., 2016). The plates were then covered with parafilm and aluminum foil for dark conditions. After gentle agitation at $21^{\circ} \mathrm{C}$ for $8-10 \mathrm{~h}$, the enzyme solution containing protoplasts was gently filtered through $75 \mathrm{~mm}$ nylon mesh into a $50 \mathrm{~mL}$ tube. These protoplasts were gently covered with $10 \mathrm{~mL}$ W5 solution (2 mM MES pH 5.7, $154 \mathrm{mM} \mathrm{NaCl}, 125 \mathrm{mM}$ $\mathrm{CaCl}_{2}$, and $5 \mathrm{mM} \mathrm{KCl}$ ) without disturbing the $21 \%$ sugar content gradient, followed by centrifugation for 8 min at $100 \times \mathrm{g}$. Approximately $10 \mathrm{~mL}$ of intact protoplasts floating on the sucrose added to $20 \mathrm{~mL}$ of W5 solution were carefully transferred to a new $50 \mathrm{~mL}$ tube. An aliquot of $15 \mathrm{~mL}$ W5 solution was added followed by centrifugation for $5 \mathrm{~min}$ at $60 \mathrm{xg}$. Subsequently, the protoplasts were washed with $15 \mathrm{~mL}$ of W5 solution and centrifuged again for $5 \mathrm{~min}$ at $60 \mathrm{xg}$. Pelleted protoplasts were resuspended in $5 \mathrm{~mL}$ MaMg solution containing $4 \mathrm{mM} \mathrm{MES} \mathrm{pH} \mathrm{5.7,} 0.4 \mathrm{M}$ mannitol and $15 \mathrm{mM} \mathrm{MgCl}_{2}$. Plasmids encoding the proteins to be expressed were transfected into protoplasts using the plasmid-PEG-calcium transfection method. Briefly, $20 \mu \mathrm{g}$ of each construct $(1 \mu \mathrm{g} / \mu \mathrm{L})$ was added to $300 \mu \mathrm{L}$ of protoplast solution and mixed gently. $320 \mu \mathrm{L}$ of PEG solution was added and gently mixed with DNA-protoplasts by tapping. This mixture was incubated at $21^{\circ} \mathrm{C}$ for $30 \mathrm{~min}$. The transfection mixture was diluted and washed with $1 \mathrm{~mL}$ W5 solution 5 times at $5 \mathrm{~min}$ intervals, then centrifugated at $50 \times \mathrm{g}$ for $4 \mathrm{~min}$ at room temperature. The protoplasts were resuspended gently with $2 \mathrm{~mL}$ W5 solution and then incubated for $24 \mathrm{~h}$ under dark conditions for further experiments. Transformed protoplasts were observed 2 days after transformation with Olympus AX-70 fluorescence microscope, and the images were captured with a cooled chargecoupled device camera (Olympus, Tokyo, Japan).

\section{Transient expression assay}

A pUC19-derived plasmid containing the GUS reporter gene under the control of a Gal4 and D1-3 minimal promoter was used as the reporter plasmid (Hwang et al., 2014). For the effector plasmids, full-length MYB3 CDNA was inserted into a plant expression vector ( $p H B T 95)$ containing the Gal4-BD domain. Effector and reporter plasmids were co-introduced into Arabidopsis protoplasts; GUS activity was 
analyzed as described previously (Hwang et al., 2014). Protoplasts were isolated from 3-week-old plants as described previously (Kim et al., 2016). In each transformation, $2 \times 10^{6}$ protoplasts were transformed using PEG with $20 \mu \mathrm{g}$ of plasmid DNA carrying a reporter plasmid plus empty effector vector or the reporter plasmid plus various effector plasmids. The transformed protoplasts were incubated in the dark at $21^{\circ} \mathrm{C}$ for $16 \mathrm{~h}$. A construct carrying the CaMV35S promoter fused to the luciferase (LUC) gene was used as an internal control in each transformation. To correct the variations in transformation efficiency, data normalization was performed by dividing the GUS activity of the cell lysate by the LUC activity.

\section{Quantitative RT-PCR (qRT-PCR) analysis}

Two-week-old seedling plants were incubated in sterile one-half-strength liquid MS at room temperature overnight. Plants were immediately harvested after treatment with $100 \mathrm{mM} \mathrm{NaCl}$ by flash-freezing in liquid nitrogen. Harvested samples were ground in a mortar and pestle with liquid nitrogen until a superfine powder. Total RNA was extracted using Trizol reagent (Invitrogen, 15596018) according to the manufacturer's instructions. The RNA concentration was estimated using nano drop and RNA was subsequently treated with Turbo DNA-free DNase (Invitrogen, AM2238). The RNA was used for first-strand cDNA synthesis using reverse transcriptase (Promega, M-MLV Reverse Transcriptase, PRM1705). The real-time PCR was performed using the SYBR ${ }^{\mathrm{TM}}$ Green PCR Master mix (Applied Biosystems, Power SYBR® Green PCR Master Mix, 4368702) following the manufacturer's instructions. RNA levels were normalized against the expression of the Actin (Actin2).

\section{Histochemical GUS staining}

Histochemical staining of GUS activity was performed as described in (Kim et al., 2016). Briefly, whole seedlings or various tissues were immersed in histochemical staining solution containing $50 \mathrm{mM} \mathrm{KH}_{2} \mathrm{PO}_{4}$ buffer ( $\mathrm{pH}$ 7.2), $2 \mathrm{mM}$ potassium ferrocyanide, $2 \mathrm{mM}$ potassium ferricyanide and $0.2 \%$ Triton $\mathrm{X}-100$ containing $1 \mathrm{mM} \mathrm{X-GlcA}$ (Duchefa, Netherlands). After incubation in a vacuum for $10 \mathrm{~min}$, the seedlings were incubated at $37^{\circ} \mathrm{C}$ for $6-12 \mathrm{~h}$ depending on staining status. Chlorophyll was cleared from the plant tissues by immersing them in $70 \%$ ethanol then washing with $70 \% \mathrm{EtOH}$ repeatedly until tissue was clear. Stained tissues were observed and digital images were obtained using an Olympus Stereo-master microscope (Olympus SZX12 stereoscope).

\section{Yeast two-hybrid assay}

In order to isolate of MYB3 interacting proteins, a yeast two-hybrid assay was performed according to Yeast Protocols Handbook (Clontech, USA). The cDNA fragment encoding MYB3 was amplified by PCR using the Arabidopsis cDNA library as a template and then ligated into the $p B U T E$ plasmid, resulting in pBUTE-MYB3 as a bait. Subsequently, the $P B U T E-M Y B 3$ construct was transformed with combinations of pACT constructs or cDNA library (activation domain; $A D$ ) into the yeast strain PJ69-4a using the PEG method and was screened via auxotrophic selection on Leu/Ura/His drop-out media containing $5 \mathrm{mM}$ of 3-amino-1,2,4-triazole (3-AT) eliminating the leaky expression of the HIS3 reporter gene. To validate 
positive interactions, the transformed $P J 69-4 a$ yeast colonies containing each construct were analyzed by auxotrophic selection and confirmed by $\beta$-galactosidase assay.

\section{Quantification of lignin contents}

The thioglycolic acid (TGA) assay was carried out according to the previously reported protocol in order to determine lignin contents (Brinkmann et al., 2002). Plants were immediately harvested by flashfreezing in liquid nitrogen. Harvested leaves were ground in a mortar and pestle with liquid nitrogen until a superfine powder. Approximately $50 \mathrm{mg}$ of powder was extracted with $70 \%$ ethanol until undetectable at $280 \mathrm{~nm}$ absorbance. The residual substance was then extracted with 100\% DMSO for $12 \mathrm{~h}$ at room temperature. This extraction step was repeated two more times until the samples were starch-free. The cell wall residues were washed six times with $70 \%$ ethanol to remove residual DMSO solution and finally washed two more times with $100 \%$ acetone. The cell wall residues were collected by centrifugation at $16,000 \times \mathrm{g}$ for $10 \mathrm{~min}$ and were air-dried. After $1 \mathrm{~mL}$ absolute methanol was added to the cell wall residues, the tube was capped, mixed to resuspend the pellet and incubated at $80^{\circ} \mathrm{C}$ for $2 \mathrm{~h}$. Insoluble materials were collected by centrifugation at $10,000 \times \mathrm{g}$ for $5 \mathrm{~min}$. The pellet was resuspended in $1 \mathrm{~mL}$ distilled water by vortexing. The pellet was then mixed with $750 \mu \mathrm{L}$ distilled water, $250 \mu \mathrm{L}$ concentrated $\mathrm{HCl}$ and $100 \mu \mathrm{L}$ thioglycolic acid. The tube was capped, mixed and incubated at $80^{\circ} \mathrm{C}$ for $3 \mathrm{~h}$. The insoluble materials were collected by centrifugation at $16,000 \mathrm{xg}$ for $15 \mathrm{~min}$, and the supernatant was discarded. The pellet was resuspended in $1 \mathrm{~mL}$ distilled water and recollected by centrifugation at 16,000 $\mathrm{x} \mathrm{g}$ for $15 \mathrm{~min}$. The resulting pellet was resuspended in $1 \mathrm{~mL} 1 \mathrm{M} \mathrm{NaOH}$. The capped tubes were gently agitated for $12 \mathrm{~h}$ at room temperature. Insoluble materials were collected by centrifugation at 10,000 $\mathrm{xg}$ for $5 \mathrm{~min}$ and the collected precipitates were removed. The supernatant was transferred to a fresh $2 \mathrm{~mL}$ tube and mixed with $200 \mu \mathrm{L}$ concentrated $\mathrm{HCl}$. The tubes were capped, shaken vigorously for $5 \mathrm{~s}$, and incubated for $4 \mathrm{~h}$ at $4^{\circ} \mathrm{C}$. The resulting precipitate was collected by centrifugation at 10,000 $\mathrm{xg}$ for 5 min. The pellet was dissolved in $1 \mathrm{~mL} \mathrm{NaOH}$. After a 50 -fold dilution with $1 \mathrm{M} \mathrm{NaOH}$, the absorbance of the samples at $280 \mathrm{~nm}$ was recorded.

\section{Quantification of anthocyanins contents}

Anthocyanins were extracted from rosette leaves of 2-week-old plants treated $\mathrm{NaCl}$ for 5 days by immersion in $99 \%$ methanol plus $1 \% \mathrm{HCl}$ at $4^{\circ} \mathrm{C}$ for $16 \mathrm{~h}$. The relative level of anthocyanin was calculated from the absorbance at 530 and $637 \mathrm{~nm}$, as described previously (Mancinelli, 1984). All experiments were independently performed 3 times (biological repeats) per treatment.

\section{Results}

\section{MYB3 forms a homodimer and the N-terminus of MYB3 is crucial for nuclear localization}

In previous reports, MYB3 is shown to serves as a transcriptional regulator and is localized to the nucleus (Bang et al., 2008; Zhou et al., 2017). In this study, we predicted the nuclear localization sequence (NLS) in the N-terminus of MYB3 using the SUBA (https://suba.live/) and NLS mapper (http://nls-mapper.iab. 
keio.ac.jp/cgi-bin/NLS_Mapper_form.cgi) programs (Supplementary Fig. S1). In order to demonstrate the NLS of MYB3, GFP fused full-MYB3, N-terminal MYB3 (1-184 a.a) and C-terminal MYB3 (185-257 a.a) were transformed into Arabidopsis protoplasts. The GFP signal was observed 48 hours after transformation. As expected, $\mathrm{N}$-terminus deleted MYB3 did not mainly localize to the nucleus but instead remained in the cytoplasm (Fig. 1a). This indicates that the NLS sequence is located at the N-terminal MYB3. In previous reports, the homo- or hetero-dimerization of transcription factors is essential for their function as a transcriptional regulator (Dubos et al., 2010). In order to determine MYB3 homodimerization, yeast two hybrid screening was performed. With this method, it was determined that MYB3 forms a homodimer. MYB32 and MYB8 were used as negative controls (Fig. 1b). These results clearly indicate that NLS is located in the N-terminus of MYB3 and that forms a homodimer in the nucleus.

\section{MYB3 is expressed in vascular tissues and is highly induced by salt and various hormones}

In order to understand tissue specific MYB3 expression patterns, GUS staining and RT-PCR were performed. To confirm this, $2 \mathrm{~kb}$ of $M Y B 3$ promoter fragments fused with the $\beta$-glucuronidase (GUS) reporter gene was prepared in order to examine the expression of $M Y B 3$. Interestingly, MYB3 is highly expressed in the flowers but weakly expressed in various tissues such as roots, leave and stems under normal growth conditions (Fig. 2a). This was confirmed by GUS staining in various tissues, especially in vascular compartments (Fig. 2b). It has previously been shown that the MYB3 is highly induced by ABA

and $\mathrm{NaCl}$ treatments in RT-PCR analysis (Bang et al., 2008). In histochemical analysis, as expected, MYB3 is highly expressed in the leave and roots under $\mathrm{NaCl}$ treatment, as well in $\mathrm{KCl}, \mathrm{LiCl}$, and mannitol treatments (Fig. 2c, d). In addition, MYB3 is not only induced by ABA but also highly expressed by various phytohormones such as a GA, SA, NAA and ethylene (Fig. 2e). Taken together, these results indicate that nuclear-localized homodimer MYB3 is highly expressed under salt conditions and when treated with several plant growth regulators and stress-responsive phytohormones.

\section{MYB3 is involved in $\mathrm{NaCl}$ response}

To understand functional characterization of MYB3, T-DNA inserted myb3 was obtained from the GabiKat collection (https://www.gabi-kat.de/) (Fig. 3a). In order to confirm the myb3 mutant, genotyping and RT-PCR were performed. As shown in Fig. 3b, T-DNA was inserted homozygously in the 3rd exon of the MYB3 chromosome (Fig. 3a, b) This was confirmed by RT-PCR analysis. As result, MYB3 was completely undetectable in this mutant, so myb3 is characterized as a knock-out mutant (Fig. 3c). In order to determine the biological role of myb3 in high salt conditions, myb3 was vertically grown in $100 \mathrm{mM} \mathrm{NaCl}$ MS media. Primary root length was significantly reduced in the myb3 mutant under $100 \mathrm{mM} \mathrm{NaCl}$ treatment (Fig. 3d, e). To identify the target genes of the MYB3 transcriptional regulator under $\mathrm{NaCl}$ stress conditions, transcriptional levels of various salt responsive genes, such as a RD29a, RD22, KIN1, KIN2 and COR 15 were examined by RT-PCR analysis. RD29a and RD22 expression was slightly higher in the myb3 background under normal growth conditions; however, most of the examined stress-responsive genes did not show significantly different levels when compared to the WT and myb3 plants under $\mathrm{NaCl}$ treatments 
(Fig. 3f). These results suggest that MYB3 may not function via an initial direct activation or repression of salt stress-responsive such genes as a transcriptional regulatory pathway.

\section{myb3 displays increased lignin content under $\mathrm{NaCl}$ treatments}

The above results show that MYB3 effects plant growth under $\mathrm{NaCl}$ treatment, but that it does not significantly regulate the expression of various salt responsive genes. So, how could the myb3 mutant show longer root growth in the NaCl-treated environment? Interestingly, MYB3 was widely detected in the vascular tissue in various organs including roots, leaves, and flowers, and its expression was highly induced by $\mathrm{NaCl}$. It has been reported that this such gene expression patterns are importantly involved in the response through the biosynthesis of lignin or anthocyanin under various stresses, especially in response to high $\mathrm{NaCl}$ conditions (Chen et al., 2020; Eryılmaz, 2006; Mahmood et al., 2016). This evidence suggests that MYB3 functions through either the synthesis of lignin or anthocyanin in vascular tissues in response to high salt stress. Firstly, lignin contents were examined with a TGA assay in WT and myb3 plants in order to investigate the relationship between MYB3 and lignin biosynthesis under $\mathrm{NaCl}$ treatments. The total lignin contents significantly increased in myb3 up to 2-fold greater than the WT plants (Fig. 4a). These results indicate that MYB3 plays an important role as a negative regulator for lignin biosynthesis in Arabidopsis. Thus, transcripts of genes related to lignin biosynthesis from both WT and myb3 plants were analyzed by RT-PCR. Transcript levels of PAL2, C4H, COMT and 4CL3 from myb3 plants were higher than those of WT plants under $\mathrm{NaCl}$ conditions (Fig. 4b). However, a significant difference in the transcript levels was not observed in CCOAOMT, CHS, F3H and F3'H compared to WT and myb3 under $\mathrm{NaCl}$ treatment (Fig. 4c). This indicates that MYB3 plays an important role as a negative regulator in lignin biosynthesis under $\mathrm{NaCl}$ stress conditions.

\section{High accumulation of anthocyanins in myb3 under high $\mathrm{NaCl}$ condition}

When plants are exposed to abiotic stresses, they may change anthocyanin contents, owing to differential expression of genes related with anthocyanin biosynthesis. Recently, MYB3 was reported to be involved in the synthesis of anthocyanins under normal growth conditions (Zhou et al., 2017). In order to analyze anthocyanin contents under $\mathrm{NaCl}$ stress conditions, anthocyanin contents were quantified in WT and myb3. Under normal conditions, anthocyanins were slightly higher in the myb3 plants as previously reported. Remarkably, anthocyanin content in myb3 were significantly higher than those in wild-type at 5 days under high salt conditions (Fig. 5a). To analyze the effect of MYB3 on the biosynthesis of anthocyanins, the transcripts of genes related with flavonoid biosynthesis, including $\angle D O X$ and DFR, were examined under normal and $\mathrm{NaCl}$ conditions. Transcripts of $L D O X$ and DFR were much highly increased under $\mathrm{NaCl}$ treatment in myb3 compared to wild-type (Figs. 5b, c). However, no significant differences were observed in the transcript levels of TTG1 between the WT and myb3 plants under normal growth or high salt conditions (Fig. 5d). These results indicate that MYB3 plays an important role as a negative regulator in both $\angle D O X$ and DFR gene expression in order to control the excessive anthocyanin accumulations in $\mathrm{NaCl}$ stress conditions. 
Transcription factors either act as activators or repressors in gene expression, and either increase or decrease transcription through sequence-specific DNA binding and protein-protein interactions. In previous work (Ambawat et al., 2013), it was described that MYB4 contains an LNL[E/D]L motif in the Cterminus which belongs to the subgroup 4 . The motif acts as a negative regulator of Cinnamate-4hydroxylase $(\mathrm{C} 4 \mathrm{H})$ in the core phenylpropanoid pathway and serves an important function in its repression activity (Wang et al., 2020). Collectively, it can be proposed that MYB3 carrying the LNL[E/D]L motif plays a role as a transcriptional repressor. To determine whether MYB3, a R2R3-type MYB transcription factor, acts as an activator or a repressor, a transactivation assay was performed. Gal4-BDMYB3 showed repression of GUS reporter gene expression when compared to the BD-Gal4 control treatment (Fig. 6a, b). To address whether the repressor domain is located in the C-terminus of MYB3, a deletion of MYB3 was constructed. As expected, transcriptional repression was abolished in the Cterminal deletion of MYB3 (Fig. 6c). In order to identify MYB3 interacting proteins, yeast-two hybrid screening was performed using the Arabidopsis CD4-10 cDNA prey library. Five individual clones, TT8 (At4g09820), EGL3 (At1g63650), MYB21 (At3g27810), ANAC096 (At5g46590) and putative MYB transcription factor (At3g10580), were isolated as putative MYB3 interacting proteins and confirmed with an X-gal test (Fig. 6d, Table 1). These results indicate that MYB3 is a transcriptional repressor that forms a hetero-oligomer with other transcription factors in the nucleus.

Table 1

Five clones obtained by yeast two-hybrid screening

\begin{tabular}{|lll|}
\hline AGI & Name & Description \\
\hline At4g09820 & bHLH42 & TRANSPARENT TESTA 8 (TT8) \\
\hline At1g63650 & bHLH2 & ENHANCER OF GLABRA 3 (EGL3) \\
\hline At3g27810 & MYB21 & MYB DOMAIN PROTEIN 21 \\
\hline At5g46590 & ANAC096 & NAC DOMAIN CONTAINING PROTEIN 96 \\
\hline At3g10580 & - & MYB-LIKE DNA-BINDING DOMAIN \\
\hline
\end{tabular}

\section{Discussion}

\section{MYB3 functions to inhibit excessive biosynthesis of lignin and anthocyanin due to high salinity conditions}

One common plant response to abiotic stressors like as high salinity is the rapid synthesizing of lignin and anthocyanin (Eryllmaz, 2006). However, excessive synthesis of lignin and anthocyanin adversely affects plant growth (Chen et al., 2020; Naing and Kim, 2021). Therefore, the synthesis of lignin and anthocyanin in such an unfavorable environment must be controlled very precisely. Recently, there has been a strong interest in research to elucidate the function of this negative transcriptional regulator. Recent studies have showed that several R2R3-type MYB transcription factors are important for the control of phenylpropanoid biosynthesis genes in plants (Cone et al., 1986; Dubos et al., 2010; Preston et 
al., 2004). For example, MYB4 and MYB32, which belong to subgroup 4 along with MYB3, regulate phenylpropanoid biosynthesis genes (Jin et al., 2000; Preston et al., 2004). It has been reported that AtMYB4 is a negative regulator of $C 4 H$, which is a gene that is involved in the upstream biosynthesis of phenylpropanoid, and that the a LNL[E/D]L motif was crucial for MYB4 function (Jin et al., 2000). In our studies, lignin contents dramatically increased in the myb3 mutant background under high salinity conditions (Fig. 4a). Furthermore, the expression of lignin biosynthesis genes such as PAL2, C4H, COMT and $4 C L 3$, were highly induced in the myb3 mutant under $\mathrm{NaCl}$ conditions. However, CCOAOMT, CHS, F3H and $\mathrm{F}^{\prime} \mathrm{H}$ were not significantly altered in myb3 (Fig. $4 \mathrm{~b}, \mathrm{c}$ ). This absence of induction of gene involved in later stages of lignin biosynthesis indicates that $M Y B 3$ is selectively involved in the regulation of early stages of lignin biosynthesis. In addition, anthocyanin contents also highly accumulated in myb3 mutant (Fig. 5a). LDOX and DFR expression in the myb3 mutant was highly induced under $\mathrm{NaCl}$ treatment (Figs. $5 b, c)$. LDOX encodes leucoanthocyanidin dioxygenase, which is involved in proanthocyanin biosynthesis. As the leucoanthocyanidin dioxygenase ( $L D O X)$ reaction produces cyanidin, the substrate for BAN, this places LDOX before BAN in the pathway (Abrahams et al., 2003). DFR encodes dihydroflavonol reductase, which catalyzes the conversion of dihydroquercetin to leucocyanidin in the biosynthesis of anthocyanins (Nesi et al., 2000). However, TTG1 was not significantly altered in myb3 mutant under $\mathrm{NaCl}$ treatment. In previous reports and our studies, it is strongly suggested that MYB3 selectively functions to inhibit excessive biosynthesis of lignin and anthocyanin under high salinity conditions.

\section{The C-terminus of MYB3 is important for its function as a repressor, and the N-terminus is essential for its nuclear localization}

Members of MYB subgroup 4 share the presence of a conserved C2 repressor core LNL[E/D]L motif associated with ethylene response factor-associated amphiphilic repression (EAR) motif (Jin et al., 2000; Kranz et al., 1998). Two Antirrhinum majus MYB factors, AmMYB308 and AmMYB330, have been reported as transcriptional repressors of lignification and phenolic acid metabolism. These MYB transcription repressors can suppress the gene expression of $C A D$ (cinnamyl alcohol dehydrogenase), $4 C L$ (4-coumarate: CoA ligase) and $\mathrm{C} 4 \mathrm{H}$ (cinnamate-4-hydroxylase) in transgenic tobacco plants (Tamagnone et al., 1998). MYB4 regulates sinapate esters involved in UV protection through downregulation of $\mathrm{C} 4 \mathrm{H}$ (cinnamate-4-hydroxylase) in Arabidopsis (Jin et al., 2000; Wang et al., 2020). The C-terminal motif, LNL[E/D]L, of AtMYB4, found to be conserved in the analysis presented here, is required for repression of transcription at target promoters (Wang et al., 2020). AtMYB3, which contains a LNL[E/D]L motif in the C-terminal region similar to MYB4 in subgroup 4, was confirmed as a transcriptional repressor by transient expression assay (Fig. 6a-c).

In previous reports, MYB3 was identified as a CPL1 phosphatase interacting partner and GFP tagged MYB3 was shown to localize in the nucleus. In order to detect the NLS signal of MYB3 in more detail, we investigated the subcellular localization of MYB3 in protoplast cells using a construct with truncated R2R3 MYB domain regions in the N-terminus or C-terminus to function as a repressor. In recent reports, the N-terminal region of poplar MYB transcription factor 3 (PtrMYB3) contained a short sequence of 
nuclear localization signal (NLS). Here, the nuclear localization signal (NLS) in the N-terminal region of MYB3 was predicted using the cNLS mapper program (http://nls-mapper.iab. keio.ac.jp/cgibin/NLS_Mapper_form.cgi). As expected, NLS is located in the N-terminus of MYB3 (Fig. 1a). Therefore, we determined the MYB3 protein as a nuclear localized transcription repressor operated by a modular system in which the functions of $\mathrm{N}$-terminus and $\mathrm{C}$-terminus are distinguished.

\section{MYB functions by interacting with other TFs in the nucleus}

In previous reports, MYB and bHLH transcription factors have been shown to interact and form transcriptional complexes that regulate anthocyanin biosynthesis in plants (Holton and Cornish, 1995; Schwinn et al., 2006). These complexes can be bound to the promoter of flavonoid genes directly. In previous studies, maize ZmC1MYB and ZmBbHLH bind to the promoter of DFR gene, a Flavonoid structural gene (Goff et al., 1992); petunia PhAN2 and PhJAF13 transcriptional regulators directly bind to the promoters of spinach DFR and ANS (Shimada et al., 2007). The WD-repeat protein and homeobox protein are also involved in anthocyanin biosynthesis; the petunia WD-repeat protein AN11 acts upstream of AN2 (de Vetten et al., 1997). In Arabidopsis, the WD-repeat protein TTG1 regulates the expression of DFR gene, while the homeobox protein ANL2 can control the anthocyanin accumulation in the subepidermal layer of leaf tissues (Shirley et al., 1995; Sompornpailin et al., 2002). In our studies, MYB3 directly interacts with TT8 and EGL3, which function in the late steps of the flavonoid biosynthesis pathway. Interestingly, the expression of DFR and $L D O X$ for anthocyanin biosynthesis genes are increased in myb3 under high salinity conditions, which result in high anthocyanin accumulation levels. Therefore, it will be an important goal in future research to reveal that MYB3 directly represses the promoters of DFR and $L D O X$ in order to control the excessive anthocyanin accumulations under $\mathrm{NaCl}$ stress conditions in plants.

In summary, we demonstrated that Arabidopsis nuclear-localized MYB3 forms homodimers, and that NLS is located its N-terminus. GUS and RT-PCR analysis shows high expression of MYB3 transcripts under $\mathrm{NaCl}$ treatment, as well as longer root growth in high salinity conditions. MYB3 may not function via an initial activation or repression of salt stress-responsive genes as a transcriptional regulator. Interestingly, high accumulation of lignin and anthocyanin content was displayed in myb3, and expression of genes related to lignin and anthocyanin biosynthesis, such as PAL 1, C4H, COMT, 4CL3, DFR and LDOX, was much higher in myb3 than that of the wild-type under $\mathrm{NaCl}$ treatment. According to protoplast analysis, MYB3 was characterized as a transcriptional repressor and its C-terminus LNL[E/D]L motif was shown to be essential for repression. Overall, these results suggest that nuclear-localized MYB3 functions as a transcriptional repressor for the precise control of lignin and anthocyanin accumulation under salinity stress conditions (Fig. 7).

\section{Declarations}

\section{Author contribution statement}


D. Kim, S.J. Jeon and S. Kim designed and mainly performed the experiments. The manuscript was written primarily by D. Kim and revised by S. Yanders, H.S. Kim and S. Kim supervised the study and edited the manuscript. All authors discussed the results and commented on the manuscript.

\section{Declaration of competing interest}

The authors declare that they have no known competing financial interests or personal relationships that could have appeared to influence the work reported in this paper.

\section{Funding}

This research was supported by grants from the National Research Foundation (NRF) of Korea funded by the Korean government (MSIT) (2020R1A2C1004560) and the Korea Research Institute of Bioscience and Biotechnology (KRIBB) Research Initiative Program (KGM5372221).

\section{References}

1. Abrahams, S., Lee, E., Walker, A.R., Tanner, G.J., Larkin, P.J., Ashton, A.R., 2003. The Arabidopsis TDS4 gene encodes leucoanthocyanidin dioxygenase (LDOX) and is essential for proanthocyanidin synthesis and vacuole development. Plant J 35, 624-636. https://doi.org/10.1046/j.1365313x.2003.01834.x

2. Ambawat, S., Sharma, P., Yadav, N.R., Yadav, R.C., 2013. MYB transcription factor genes as regulators for plant responses: an overview. Physiol Mol Biol Plants 19, 307-321. https://doi.org/10.1007/s12298-013-0179-1

3. Bang, W.Y., Kim, S.W., Jeong, I.S., Koiwa, H., Bahk, J.D., 2008. The C-terminal region (640-967) of Arabidopsis CPL1 interacts with the abiotic stress- and ABA-responsive transcription factors. Biochem Biophys Res Commun 372, 907-912. https://doi.org/10.1016/j.bbrc.2008.05.161

4. Biała, W., Jasiński, M., 2018. The Phenylpropanoid Case - It Is Transport That Matters. Frontiers in Plant Science 9.

5. Brinkmann, K., Blaschke, L., Polle, A., 2002. Comparison of different methods for lignin determination as a basis for calibration of near-infrared reflectance spectroscopy and implications of lignoproteins. J Chem Ecol 28, 2483-2501. https://doi.org/10.1023/a:1021484002582

6. Century, K., Reuber, T.L., Ratcliffe, O.J., 2008. Regulating the Regulators: The Future Prospects for Transcription-Factor-Based Agricultural Biotechnology Products. Plant Physiology 147, 20-29. https://doi.org/10.1104/pp.108.117887

7. Chen, K., Guo, Y., Song, M., Liu, L., Xue, H., Dai, H., Zhang, Z., 2020. Dual role of MdSND1 in the biosynthesis of lignin and in signal transduction in response to salt and osmotic stress in apple. Hortic Res 7, 1-13. https://doi.org/10.1038/s41438-020-00433-7

8. Cominelli, E., Galbiati, M., Vavasseur, A., Conti, L., Sala, T., Vuylsteke, M., Leonhardt, N., Dellaporta, S.L., Tonelli, C., 2005. A Guard-Cell-Specific MYB Transcription Factor Regulates Stomatal 
Movements and Plant Drought Tolerance. Current Biology 15, 1196-1200.

https://doi.org/10.1016/j.cub.2005.05.048

9. Cone, K.C., Burr, F.A., Burr, B., 1986. Molecular analysis of the maize anthocyanin regulatory locus C1. Proc Natl Acad Sci U S A 83, 9631-9635. https://doi.org/10.1073/pnas.83.24.9631

10. de Vetten, N., Quattrocchio, F., Mol, J., Koes, R., 1997. The an11 locus controlling flower pigmentation in petunia encodes a novel WD-repeat protein conserved in yeast, plants, and animals. Genes Dev 11, 1422-1434. https://doi.org/10.1101/gad.11.11.1422

11. Dubos, C., Stracke, R., Grotewold, E., Weisshaar, B., Martin, C., Lepiniec, L., 2010. MYB transcription factors in Arabidopsis. Trends Plant Sci 15, 573-581. https://doi.org/10.1016/j.tplants.2010.06.005

12. Eryılmaz, F., 2006. The Relationships between Salt Stress and Anthocyanin Content in Higher Plants. Biotechnology \& Biotechnological Equipment 20, 47-52. https://doi.org/10.1080/13102818.2006.10817303

13. Fraser, C.M., Chapple, C., 2011. The Phenylpropanoid Pathway in Arabidopsis. Arabidopsis Book 9 , e0152. https://doi.org/10.1199/tab.0152

14. Goff, S.A., Cone, K.C., Chandler, V.L., 1992. Functional analysis of the transcriptional activator encoded by the maize $B$ gene: evidence for a direct functional interaction between two classes of regulatory proteins. Genes Dev 6, 864-875. https://doi.org/10.1101/gad.6.5.864

15. Gonzalez, A., Zhao, M., Leavitt, J.M., Lloyd, A.M., 2008. Regulation of the anthocyanin biosynthetic pathway by the TTG1/bHLH/Myb transcriptional complex in Arabidopsis seedlings. Plant J 53, 814827. https://doi.org/10.1111/j.1365-313X.2007.03373.x

16. Holton, T.A., Cornish, E.C., 1995. Genetics and Biochemistry of Anthocyanin Biosynthesis. Plant Cell 7, 1071-1083. https://doi.org/10.1105/tpc.7.7.1071

17. Hwang, S.M., Kim, D.W., Woo, M.S., Jeong, H.S., Son, Y.S., Akhter, S., Choi, G.J., Bahk, J.D., 2014. Functional characterization of Arabidopsis HsfA6a as a heat-shock transcription factor under high salinity and dehydration conditions. Plant Cell Environ 37, 1202-1222.

https://doi.org/10.1111/pce.12228

18. Jacob, P., Brisou, G., Dalmais, M., Thévenin, J., van der Wal, F., Latrasse, D., Suresh Devani, R., Benhamed, M., Dubreucq, B., Boualem, A., Lepiniec, L., Immink, R.G.H., Hirt, H., Bendahmane, A., 2021. The Seed Development Factors TT2 and MYB5 Regulate Heat Stress Response in Arabidopsis. Genes (Basel) 12, 746. https://doi.org/10.3390/genes12050746

19. Jin, H., Cominelli, E., Bailey, P., Parr, A., Mehrtens, F., Jones, J., Tonelli, C., Weisshaar, B., Martin, C., 2000. Transcriptional repression by AtMYB4 controls production of UV-protecting sunscreens in Arabidopsis. EMBO J 19, 6150-6161. https://doi.org/10.1093/emboj/19.22.6150

20. Katiyar, A., Smita, S., Lenka, S.K., Rajwanshi, R., Chinnusamy, V., Bansal, K.C., 2012. Genome-wide classification and expression analysis of MYB transcription factor families in rice and Arabidopsis. BMC Genomics 13, 544. https://doi.org/10.1186/1471-2164-13-544

21. Kim, D.W., Jeon, S.J., Hwang, S.M., Hong, J.C., Bahk, J.D., 2016. The C3H-type zinc finger protein GDS1/C3H42 is a nuclear-speckle-localized protein that is essential for normal growth and 
development in Arabidopsis. Plant Sci 250, 141-153. https://doi.org/10.1016/j.plantsci.2016.06.010

22. Kranz, H.D., Denekamp, M., Greco, R., Jin, H., Leyva, A., Meissner, R.C., Petroni, K., Urzainqui, A., Bevan, M., Martin, C., Smeekens, S., Tonelli, C., Paz-Ares, J., Weisshaar, B., 1998. Towards functional characterisation of the members of the R2R3-MYB gene family from Arabidopsis thaliana. Plant $\mathrm{J}$ 16, 263-276. https://doi.org/10.1046/j.1365-313x.1998.00278.x

23. Mahmood, K., Xu, Z., El-Kereamy, A., Casaretto, J.A., Rothstein, S.J., 2016. The Arabidopsis Transcription Factor ANAC032 Represses Anthocyanin Biosynthesis in Response to High Sucrose and Oxidative and Abiotic Stresses. Frontiers in Plant Science 7.

24. Mancinelli, A.L., 1984. Photoregulation of Anthocyanin Synthesis 1: VIII. Effect of Light Pretreatments. Plant Physiology 75, 447-453. https://doi.org/10.1104/pp.75.2.447

25. Naing, A.H., Kim, C.K., 2021. Abiotic stress-induced anthocyanins in plants: Their role in tolerance to abiotic stresses. Physiol Plant 172, 1711-1723. https://doi.org/10.1111/ppl.13373

26. Nesi, N., Debeaujon, I., Jond, C., Pelletier, G., Caboche, M., Lepiniec, L., 2000. The TT8 gene encodes a basic helix-loop-helix domain protein required for expression of DFR and BAN genes in Arabidopsis siliques. Plant Cell 12, 1863-1878. https://doi.org/10.1105/tpc.12.10.1863

27. Preston, J., Wheeler, J., Heazlewood, J., Li, S.F., Parish, R.W., 2004. AtMYB32 is required for normal pollen development in Arabidopsis thaliana. Plant J 40, 979-995. https://doi.org/10.1111/j.1365313X.2004.02280.x

28. Schwinn, K., Venail, J., Shang, Y., Mackay, S., Alm, V., Butelli, E., Oyama, R., Bailey, P., Davies, K., Martin, C., 2006. A small family of MYB-regulatory genes controls floral pigmentation intensity and patterning in the genus Antirrhinum. Plant Cell 18, 831-851. https://doi.org/10.1105/tpc.105.039255

29. Segarra, G., Van der Ent, S., Trillas, I., Pieterse, C.M.J., 2009. MYB72, a node of convergence in induced systemic resistance triggered by a fungal and a bacterial beneficial microbe. Plant Biol (Stuttg) 11, 90-96. https://doi.org/10.1111/j.1438-8677.2008.00162.x

30. Seo, P.J., Park, C.-M., 2010. MYB96-mediated abscisic acid signals induce pathogen resistance response by promoting salicylic acid biosynthesis in Arabidopsis. New Phytologist 186, 471-483. https://doi.org/10.1111/j.1469-8137.2010.03183.x

31. Shimada, S., Otsuki, H., Sakuta, M., 2007. Transcriptional control of anthocyanin biosynthetic genes in the Caryophyllales. J Exp Bot 58, 957-967. https://doi.org/10.1093/jxb/erl256

32. Shirley, B.W., Kubasek, W.L., Storz, G., Bruggemann, E., Koornneef, M., Ausubel, F.M., Goodman, H.M., 1995. Analysis of Arabidopsis mutants deficient in flavonoid biosynthesis. Plant J 8, 659-671. https://doi.org/10.1046/j.1365-313x.1995.08050659.x

33. Sompornpailin, K., Makita, Y., Yamazaki, M., Saito, K., 2002. A WD-repeat-containing putative regulatory protein in anthocyanin biosynthesis in Perilla frutescens. Plant Mol Biol 50, 485-495. https://doi.org/10.1023/a:1019850921627

34. Spitz, F., Furlong, E.E.M., 2012. Transcription factors: from enhancer binding to developmental control. Nat Rev Genet 13,613-626. https://doi.org/10.1038/nrg3207 
35. Stracke, R., Ishihara, H., Huep, G., Barsch, A., Mehrtens, F., Niehaus, K., Weisshaar, B., 2007. Differential regulation of closely related R2R3-MYB transcription factors controls flavonol accumulation in different parts of the Arabidopsis thaliana seedling. Plant J 50, 660-677. https://doi.org/10.1111/j.1365-313X.2007.03078.x

36. Tamagnone, null, Merida, null, Parr, null, Mackay, null, Culianez-Macia, null, Roberts, null, Martin, null, 1998. The AmMYB308 and AmMYB330 transcription factors from antirrhinum regulate phenylpropanoid and lignin biosynthesis in transgenic tobacco. Plant Cell 10, 135-154. https://doi.org/10.1105/tpc.10.2.135

37. Van der Ent, S., Verhagen, B.W.M., Van Doorn, R., Bakker, D., Verlaan, M.G., Pel, M.J.C., Joosten, R.G., Proveniers, M.C.G., Van Loon, L.C., Ton, J., Pieterse, C.M.J., 2008. MYB72 is required in early signaling steps of rhizobacteria-induced systemic resistance in Arabidopsis. Plant Physiol 146, 1293-1304. https://doi.org/10.1104/pp.107.113829

38. Vogt, T., 2010. Phenylpropanoid Biosynthesis. Molecular Plant 3, 2-20. https://doi.org/10.1093/mp/ssp106

39. Wang, X.-C., Wu, J., Guan, M.-L., Zhao, C.-H., Geng, P., Zhao, Q., 2020. Arabidopsis MYB4 plays dual roles in flavonoid biosynthesis. Plant J 101, 637-652. https://doi.org/10.1111/tpj.14570

40. Xu, W., Grain, D., Bobet, S., Le Gourrierec, J., Thévenin, J., Kelemen, Z., Lepiniec, L., Dubos, C., 2014. Complexity and robustness of the flavonoid transcriptional regulatory network revealed by comprehensive analyses of MYB-bHLH-WDR complexes and their targets in Arabidopsis seed. New Phytol 202, 132-144. https://doi.org/10.1111/nph.12620

41. Zhou, M., Zhang, K., Sun, Z., Yan, M., Chen, C., Zhang, X., Tang, Y., Wu, Y., 2017. LNK1 and LNK2 Corepressors Interact with the MYB3 Transcription Factor in Phenylpropanoid Biosynthesis. Plant Physiol 174, 1348-1358. https://doi.org/10.1104/pp.17.00160

\section{Figures}



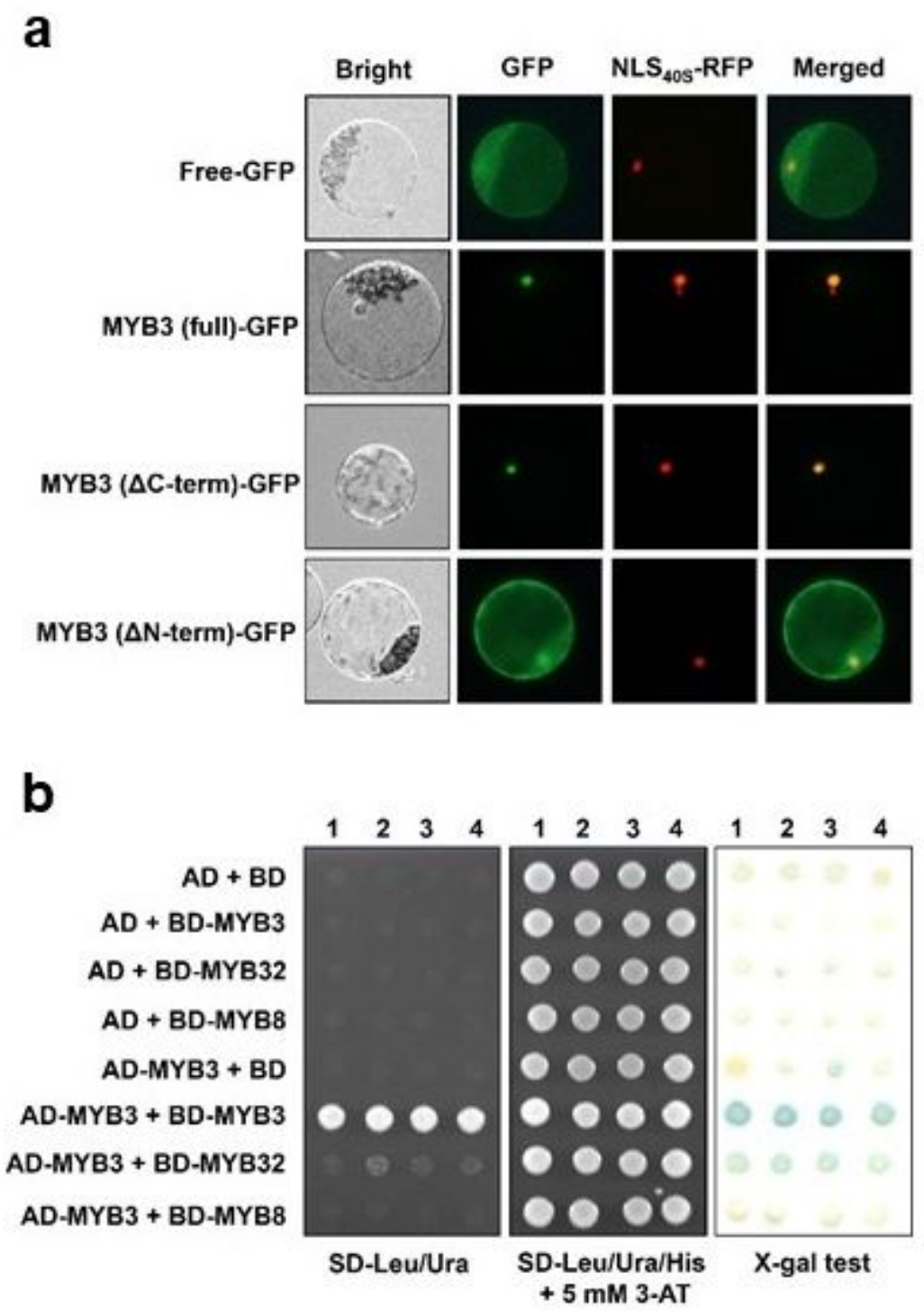

\section{Fig. 1}

\section{Figure 1}

Analysis of MYB3 subcellular localization and homodimerization. a Nuclear localization signal (NLS) is located in the N-terminus of MYB3. Full-length and two deletion versions of GFP-tagged MYB3 were introduced into Arabidopsis protoplasts using the polyethylene glycol method. NLS $S_{S V 40}-R F P$ was used as a nuclear marker. $\mathbf{b}$ Homodimerization of MYB3. Four colonies were repeatedly tested in this experiment. Confirmation of MYB3 homodimerization by the auxotrophic assay. Ten-fold serial dilutions of yeast cells were spotted on leucine and uracil drop-out medium (SD-Leu/Ura) and leucine, uracil and histidine drop- 
out (SD-Leu/Ura/His + $5 \mathrm{mM}$ 3-AT) plates. MYB32 and MYB8 were used as negative controls. The plates were incubated for five days, after which the plants underwent a $\beta$-galactosidase assay (right panel).
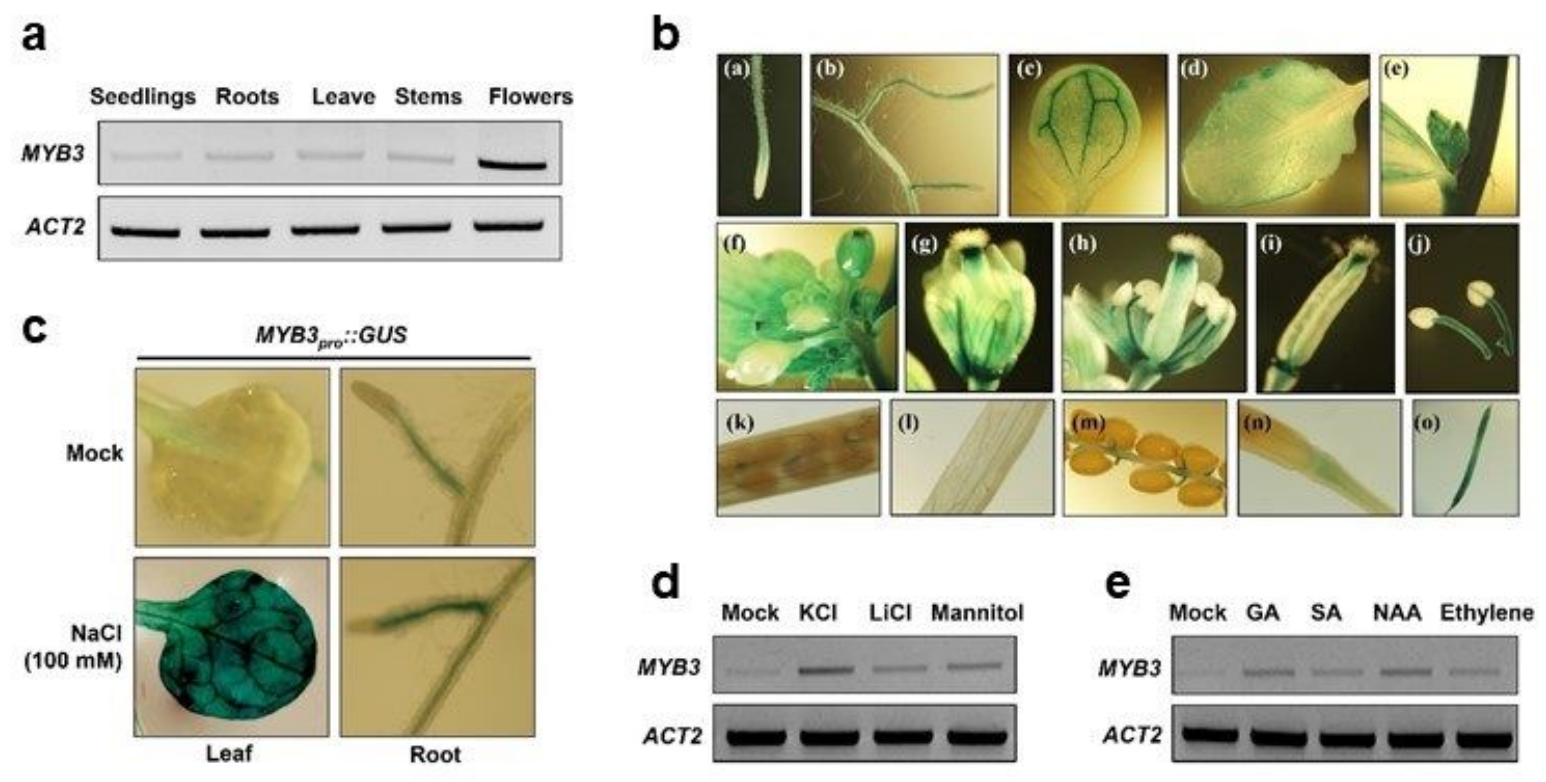

Fig. 2

Figure 2

Expression patterns of MYB3. a Tissue specific expression patterns of MYB3. Total RNA was extracted from the organs indicated above the lanes and subsequently subjected to RT-PCR using MYB3 genespecific primers. Actin (ACT2) was used as a loading control. b Analysis of GUS activity driven by a MYB3 promoter in various organs and developmental stages. In transgenic Arabidopsis expressing the GUS reporter gene driven by the MYB3 promoter, GUS activity was observed in various organs in transgenic plants, including primary root (a), lateral root (b), cotyledon (c), rosette leaf (d), inflorescence node (e), flowers buds (f), flower (h), stigma (i), stamen (j), silique coat $(k, I)$, seeds $(m)$, pedicel $(n)$ and siliques (o). c Analysis of GUS activity driven by $M Y B 3$ promoter under $\mathrm{NaCl}$ treatment. $\mathbf{d}$, e Gene expression patterns of $M Y B 3$ under various abiotic stresses and phytohormones. Total RNA was extracted from the abiotic stresses and phytohormones treatments indicated above the lanes and subsequently subjected to RT-PCR using MYB3 gene-specific primers. Actin (ACT2) was used as a loading control. 
a

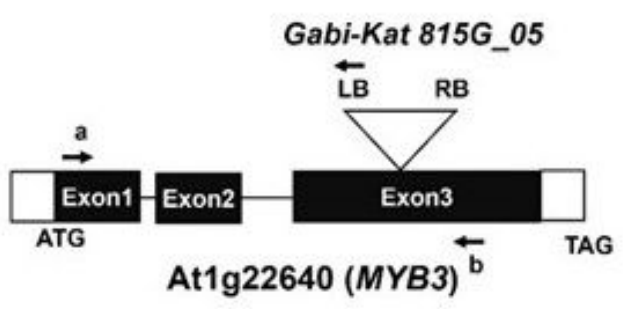

b

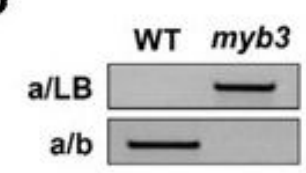

C

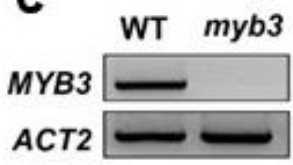

d

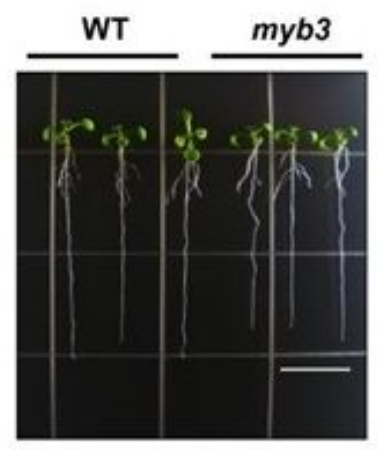

$0 \mathrm{mM}$

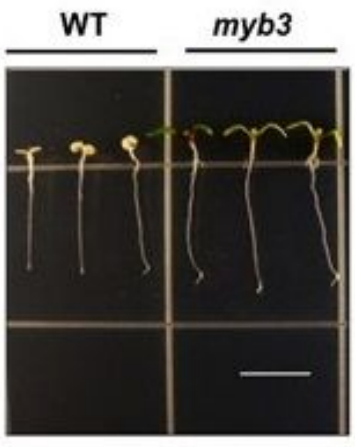

$100 \mathrm{mM}$ e

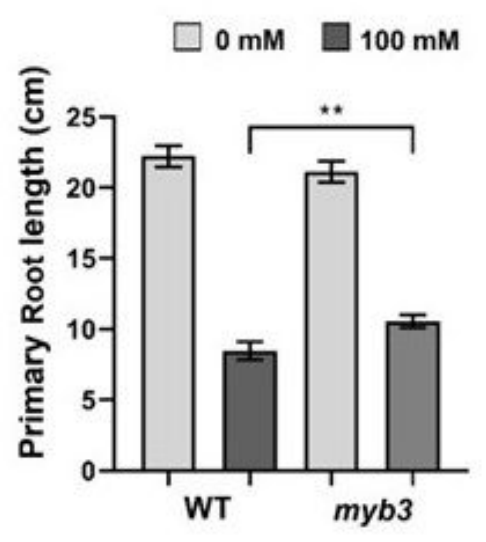

f
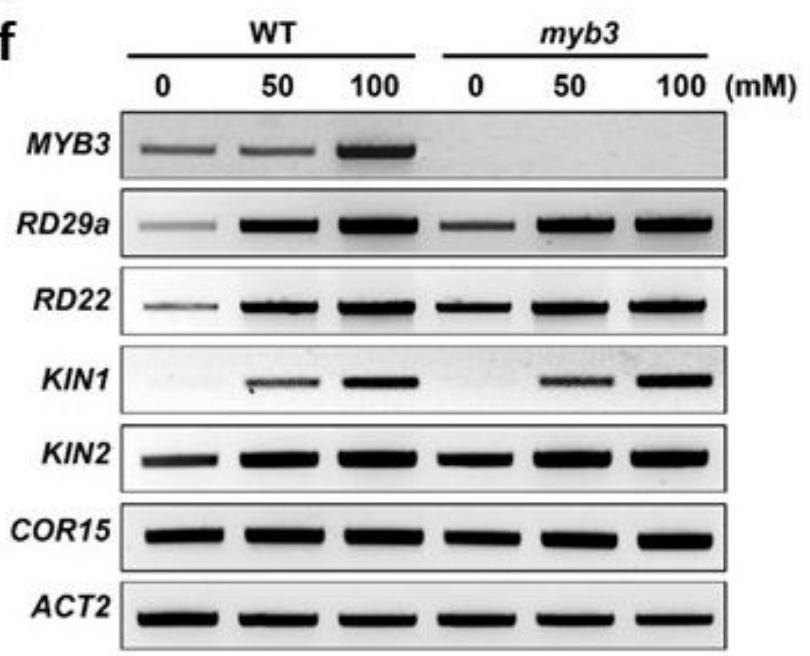

Fig. 3

\section{Figure 3}

Biological function of MYB3 in high salinity stress conditions. a Schematic diagram of the T-DNA insertion region of MYB. a, b and LB primers were used for genotyping and RT-PCR analysis. Black and white boxes represent exon and untranslated regions (UTRs), respectively. The position of the T-DNA insertion is indicated by an inverted open triangle. The myb3 mutant (Gabi-Kat 815G_05) was purchased from the Gabi-Kat collection. T-DNA was inserted at the third exon of MYB3 (At1g22640). b Analysis of homozygous myb3 by genotyping. Total genomic DNA was isolated from 10 day-old seedling plants. PCR was performed with a set of gene specific primers $(a+b$; upper) and gene-specific and T-DNAspecific primers (a + LB; lower) for MYB3 and the junction of the T-DNA region (designated in Fig. $3 A$ ) in MYB3 amplification, respectively. $\mathrm{c}$ Investigation of MYB3 transcript levels in myb3 using RT-PCR analysis. Total RNA was isolated from 10-day-old plants. Actin (ACT2) was used as a loading control. d Primary root growth of myb3 under $\mathrm{NaCl}$ treatment. The plants were vertically grown on $1 / 2 \mathrm{MS}$ medium 
with $100 \mathrm{mM} \mathrm{NaCl}$. Scale bars ( $6 \mathrm{~mm}$; left, $4 \mathrm{~mm}$; right). e Quantification of primary root length of myb3 under $\mathrm{NaCl}$ treatment. Primary root length was quantified using the ImageJ program and analyzed using the GraphPad Prism 8. Data shown as mean \pm SEM, $(n \geq 19), * P<0.05,{ }^{*} P<0.01, p$-value indicates significance relative to wild-type plants and was determined by one-sided ANOVA with unpaired, two-way Student's $t$ test. $\mathbf{f}$ Investigation of transcript levels of various stress-responsive genes in myb3 using RTPCR analysis. Total RNA was isolated from 10-day-old plants. Actin (ACT2) was used as a loading control.
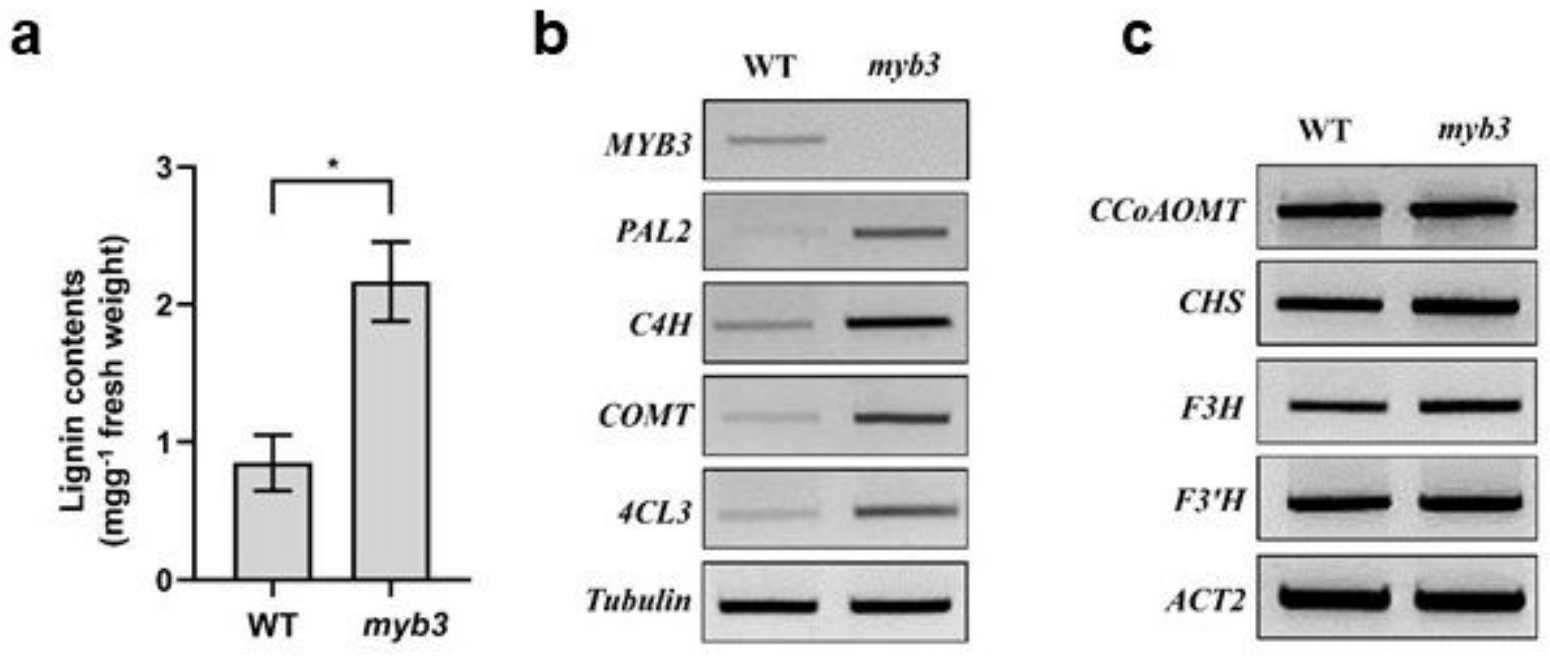

\section{Fig. 4}

\section{Figure 4}

MYB3 negatively regulates lignin biosynthesis. a Quantification of lignin contents in myb3. Thioglycolic acid (TGA) lignin contents were analyzed in whole plants. Individual lignin content was quantified using the ImageJ program and analyzed using the GraphPad Prism 8. Data shown as mean \pm SEM, $(n=3$; biological repeats), ${ }^{*} P<0.05, p$-value indicates significance relative to wild-type plants and was determined by one-sided ANOVA with unpaired, two-tailed Student's $t$ test. b, $\mathbf{c}$ Several transcripts involved in lignin biosynthesis in WT and myb3 were analyzed by RT-PCR. Tubulin and Actin (ACT2) were used as loading controls, respectively. 
a

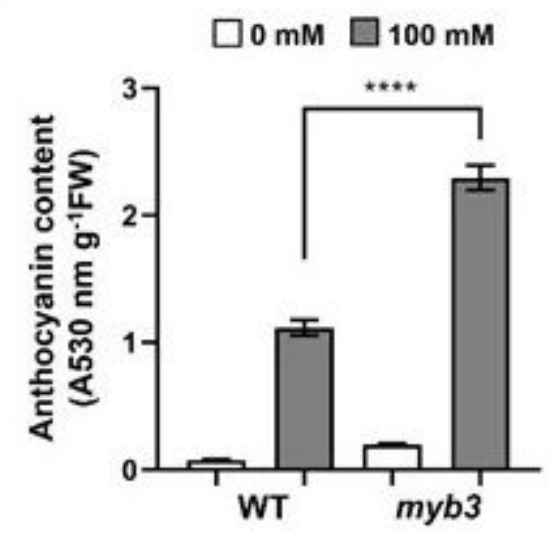

C

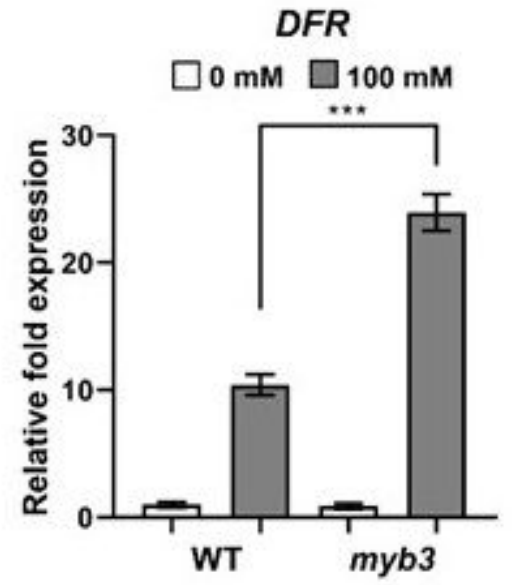

b

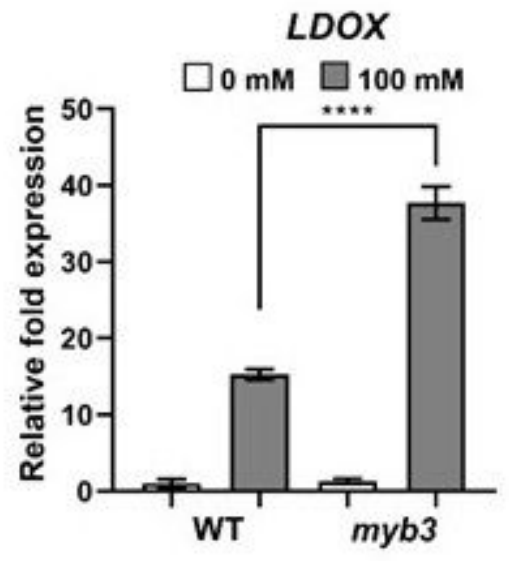

d TTG1

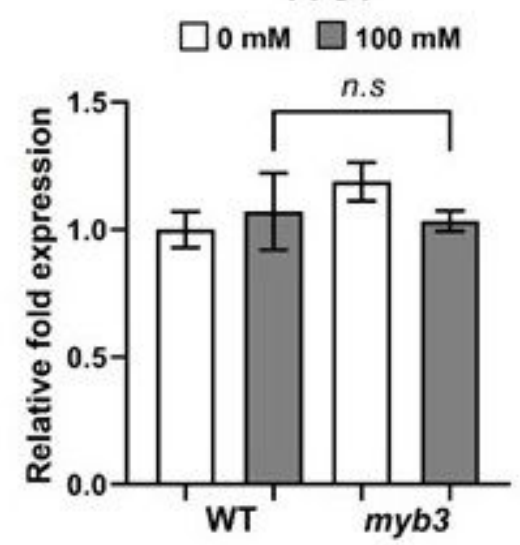

Fig. 5

\section{Figure 5}

Anthocyanin is accumulated in myb3 under $\mathrm{NaCl}$ treatment. a Quantification of anthocyanin content under salinity stress conditions. Two-week-old Arabidopsis plants were treated with $100 \mathrm{mM} \mathrm{NaCl}$ for 5 days, ( $n=5$; biological repeats). $b$-d Distinct gene expression patterns of anthocyanin biosynthesis genes in myb3 under stress conditions ( $\mathrm{n}=3$ ). Relative transcript levels were normalized to ACT2. In above graphs, individual anthocyanin content or anthocyanin biosynthesis genes were quantified using the ImageJ and Excel programs, and analyzed using the GraphPad Prism 8. Data shown as mean \pm SEM, ${ }^{*} \mathrm{P}<0.05,{ }^{*} \mathrm{P}<0.01,{ }^{* \star *} \mathrm{P}<0.001,{ }^{*} * \star \mathrm{P}<0.0001, p$-value indicates significance relative to wild-type plants and was determined by one-sided ANOVA with unpaired, two-tailed Student's $t$ test. 
a

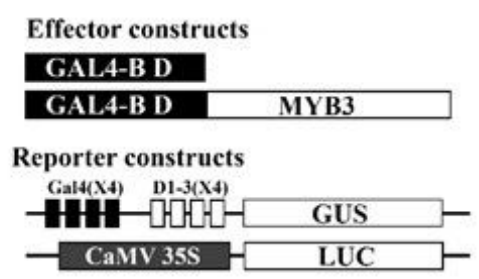

b

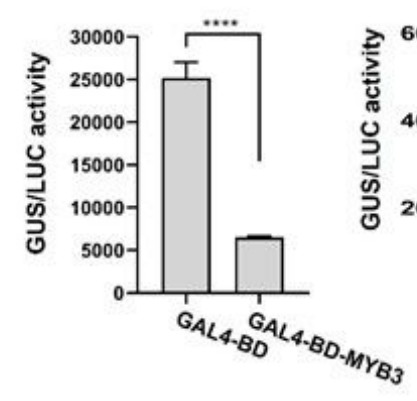

C

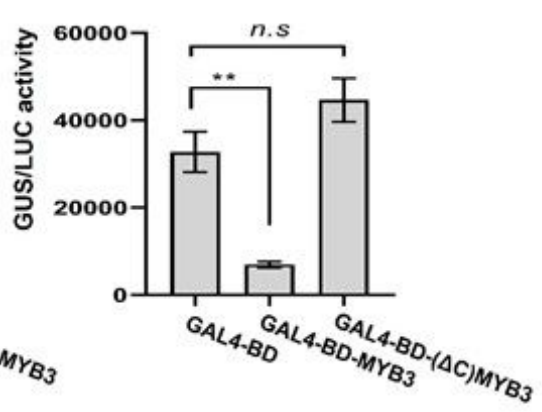

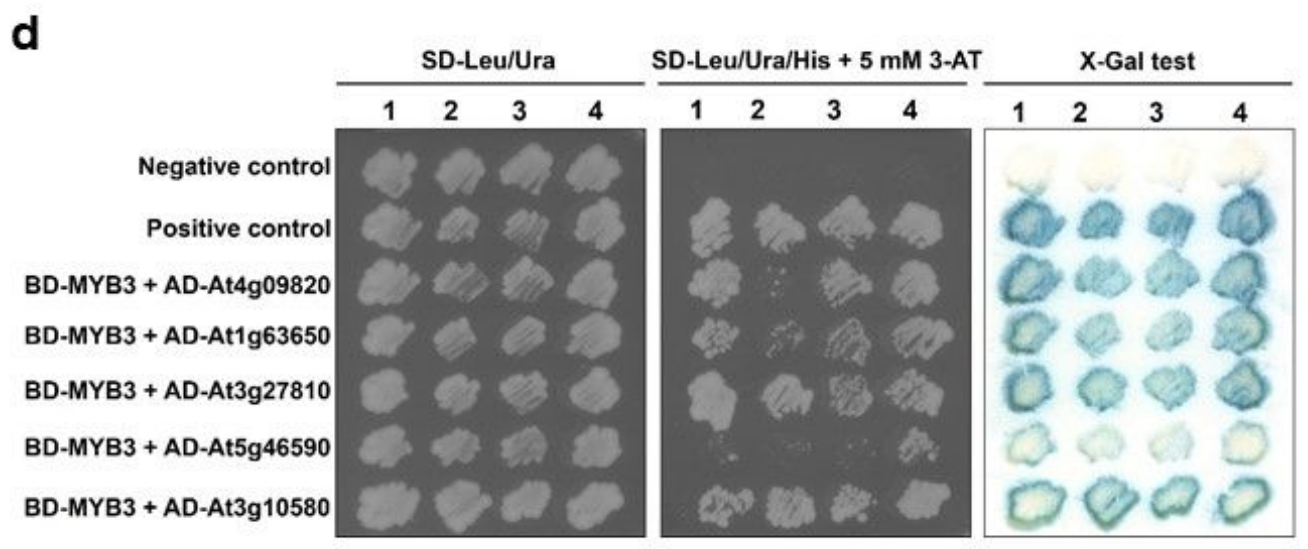

Fig. 6

\section{Figure 6}

Transcriptional repressor MYB3 interacts with several transcription factors. a Schematic diagram showing the different portions of MYB3 fused with Gal4-DBD used for analysis of transcriptional activity in Arabidopsis protoplasts. b MYB3 functions as a transcriptional repressor. Relative GUS activity was measured by transient expression assay. Arabidopsis leaf protoplasts were co-transfected with an effector and two reporter genes. Effector genes containing yeast Gal4-DBD were fused in-frame with either only Gal4-DBD or Gal4-BD-MYB3 $(n=5)$. c C-terminus of MYB acts as a repressior domain. Nterminal (1-184 a.a) and C-terminal MYB3 (185-257 a.a) were used in this experiment. The signals were normalized by luminescence. In panel $B$ and $C$, data shown as mean $\pm S E M, * P<0.05,{ }^{*} P<0.01$, $\star \star \star * P<0.001,{ }^{* \star \star *} \mathrm{P}<0.0001, p$-value indicates significance relative to Gal4-BD and was determined by onesided ANOVA with unpaired, two-tailed Student's $t$ test. $\mathbf{d}$ Isolation of MYB3 interacting proteins using yeast two-hybrid screening. Four colonies were repeatedly tested in this experiment. Description of AGI number is shown in Table 1. Auxotrophic assays were used for further confirmation. MYB8 and CPL1 were used as negative control and positive control, respectively. The plates were incubated for five days, after which the plants underwent a $\beta$-galactosidase assay (right panel). 


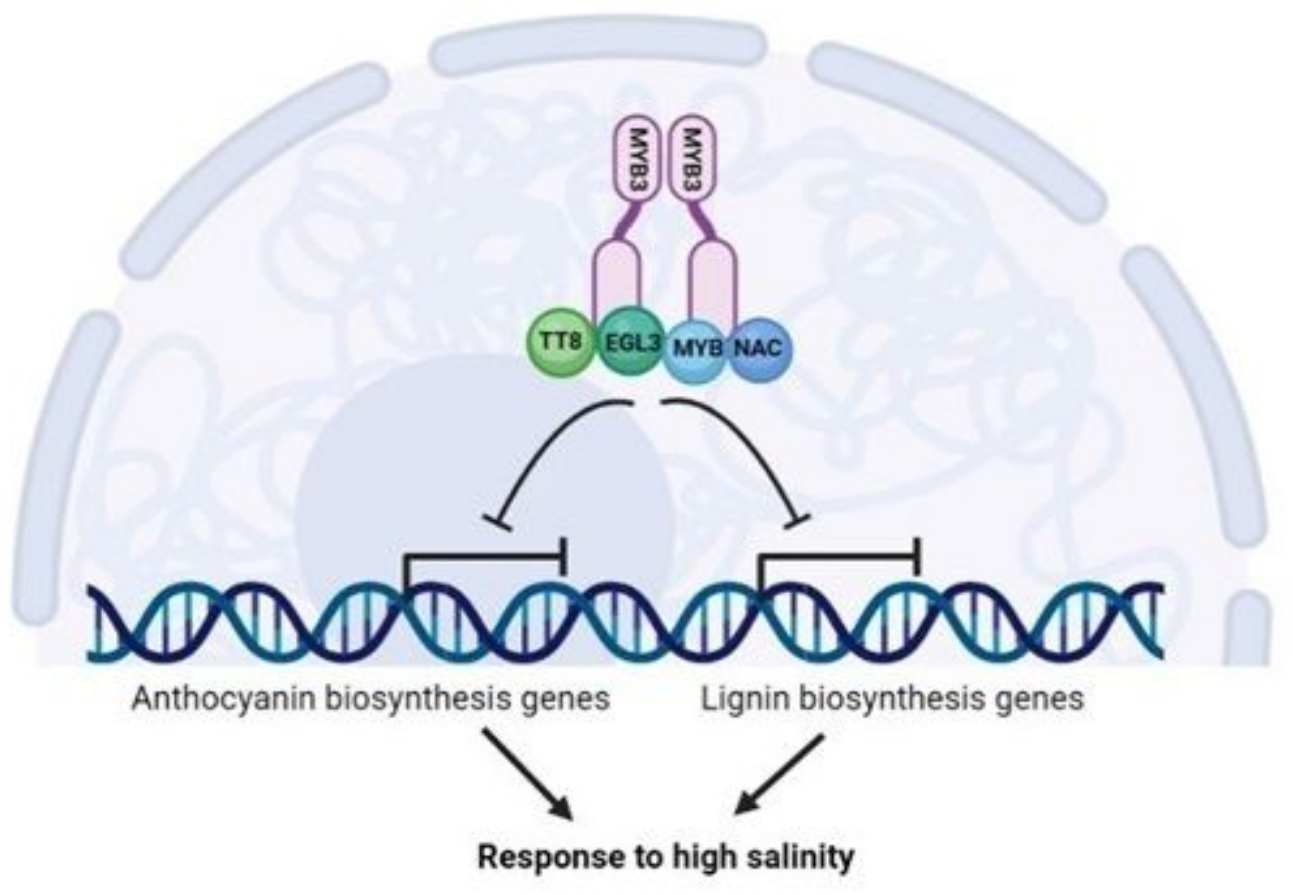

Fig. 7

\section{Figure 7}

Hypothetical model of MYB3. Nuclear-localized MYB3 transcriptional repressor interacts with TT8, EGL3, MYB and NAC transcription factors to regulate anthocyanin and lignin biosynthesis under high salinity conditions.

\section{Supplementary Files}

This is a list of supplementary files associated with this preprint. Click to download.

- SupplementaryFigureKimetal.docx 